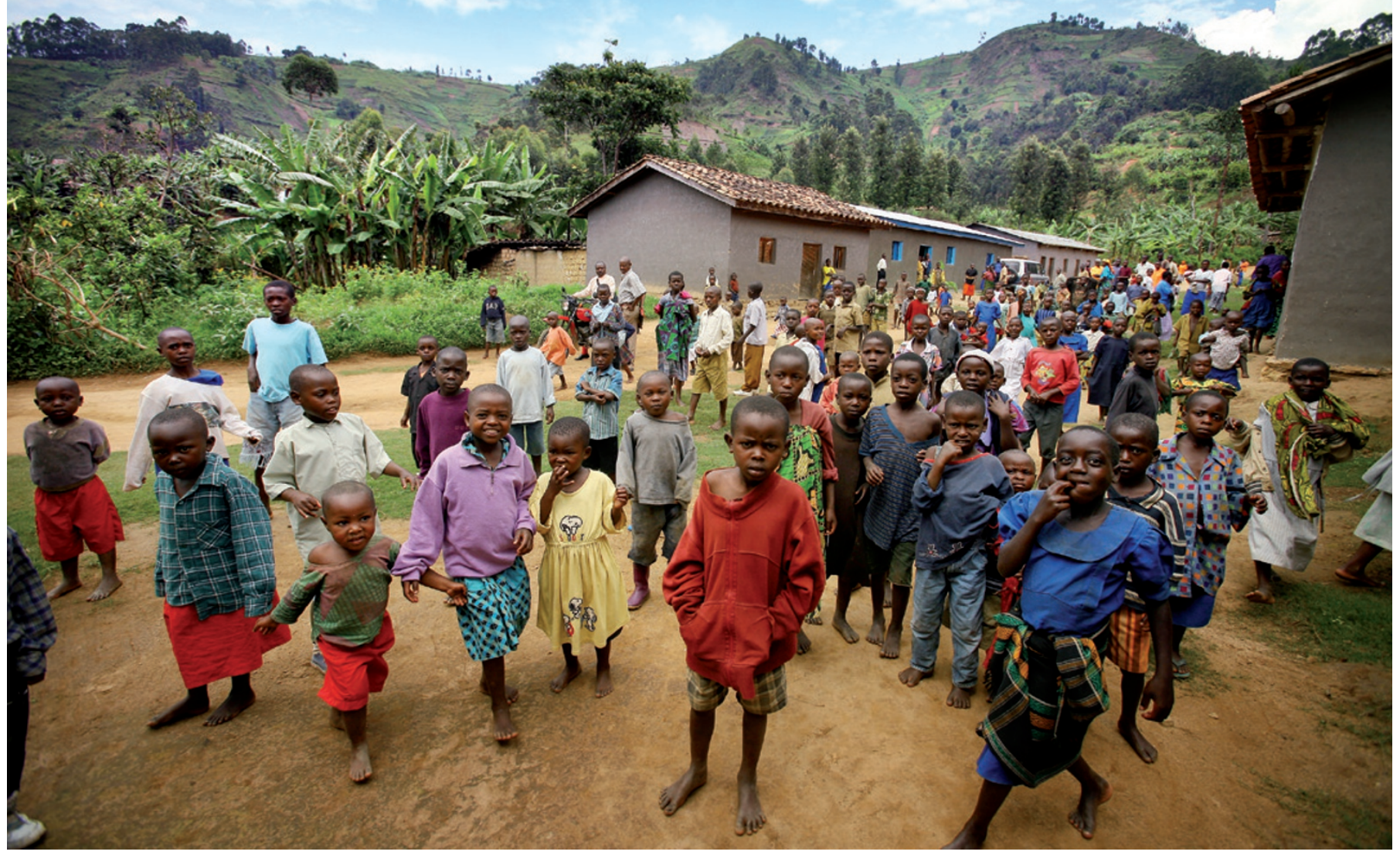

With 11 million people packed into a small nation, Rwanda is hoping to lower its high fertility rate so that it can benefit from future economic growth.

\title{
Crowd control in Rwanda
}

\section{Sub-Saharan Africa's most densely peopled mainland nation is determined to head off a population crisis. Others should take note, say Josh Ruxin and Antoinette Habinshuti.}

$\mathrm{T}$ here are few places in the world where the full pressure of population growth is felt as strongly as in tiny, landlocked Rwanda. Known for the 1994 genocide (which some claim was partly caused by population pressures), Rwanda is the most densely populated mainland nation in sub-Saharan Africa, packing more than 11 million people into an area smaller than than that of Belgium. Today it boasts economic growth, security and rising prosperity. Nonetheless, its politicians and citizens are keenly aware that their country - with the 15th highest fertility rate in the world - is nearing a population crisis. United Nations' projections indicate that if the population continues to grow at its current rate of nearly $3 \%$ a year, it could exceed 40 million by 2100 , giving the nation a density five times that of Japan's today.

The situation in Rwanda is forcing reality and political pragmatism together more rapidly than in neighbouring countries. The choices are stark: restrict population growth or remain in poverty, without the capacity to support either a growing population or an emergent economy. Rwanda is determined to do what works. Policies such as educating girls and women, and pushing for prosperity, are accepted by all. Others, such as making contraception freely and widely available, remain low priorities for international donors. The lesson from Rwanda for other nations is that without coordinated efforts on all these fronts, population growth will swallow up a country's potential.

\section{THE CHALLENGES}

Rwanda is a small country, and one of the world's fastest growing. Women in rural areas have an average of 6.3 children, and those in urban areas have an average of 4.9 (compared with Begium's average of 1.9). Today, $80 \%$ of the population lives in rural areas, where poverty tends to be more prevalent. A rural family of eight is generally confined to a plot of less than half a hectare - which, even if well cultivated, scarcely provides for their nutritional needs. These factors lead to malnutrition and stunted growth.

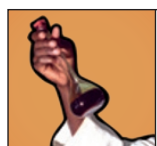

\section{SCIENCE IN AFRICA}

For more content, go to: nature.com/africa
Meanwhile, massive improvements in the country's public-health system have led to dramatic declines in infant and child mortality. For instance, mortality among under-fives dropped from 152 per 1,000 in 2005 to 103 in 2008. More children surviving means that many more people will be having children, and the country's resources will be increasingly taxed. This makes it much harder for Rwanda to deliver real prosperity to its people.

The conflict between population and economic growth is nowhere more apparent than in tourism. One of Rwanda's main industries, tourism has grown rapidly since the genocide. However, the country's only major wildlife park, Akagera National Park, was whittled down to one-third of its original size in 1997 to provide adequate farmland for thousands of post-genocide returnees. Poaching and encroachment have risen, and are particularly marked on the doorstep of the Virunga National Park, home of the renowned 'gorillas in the mist' that brought tens of millions of tourist dollars into the country last year. Farmland rolls right up to a stone wall that demarcates the park, and the gorillas frequently forage 
outside their zone, coming into greater contact with people and their diseases.

\section{THE SOLUTIONS}

Other fast-growing countries have made progress in controlling their populations. Starting in the mid-1970s, Bangladesh, which has a gross national income per capita just a little higher than that of Rwanda, used female outreach workers and mass-media campaigns to change attitudes about family size. Contraception use by married couples rose from just $8 \%$ to about $60 \%$ in 2004 , and the average number of children per woman dropped from 6 to 3 .

This success inspired the Navrongo project in Ghana in the early 1990s, which reduced family sizes from about 6.5 to 4.5 . Unlike other initiatives, the project sought to influence reproductive choices by engaging community leaders, chiefs and elders and creating 'community health compounds' to serve as village clinics.

In Bangladesh, evidence from early interventions was used to influence national policies in a top-down way. Sadly, in Ghana, hopes of turning the Navrongo project into government policy lost momentum - not because of a lack of results, but because of a loss of political will.

Indeed, too often in African nations, the will to support family planning is lacking because of religious belief, neglect or the assumption that a populous nation will be more prosperous. For example, Uganda's President Yoweri Museveni has repeatedly declared that his country, home to one of the world's fastest-growing populations, is "underpopulated".

So what is the Rwandan government to do? In our view, the lessons from Bangladesh and elsewhere are clear. First, economic growth and educational achievement (particularly in women) strongly correlates with a decline in the fertility rate. Second, mere access to free family planning - even in the poor - usually results in rapid uptake. Together, these offer a simple recipe: grow your economy, educate your girls and offer free contraceptives in every health centre and through every community health worker. That will get you $90 \%$ of the way.

Rwanda already has ambitious economic and education goals: it aims to grow its economy by $8 \%$ per year and to ensure that by 2015 every child is getting nine years of basic education and that $90 \%$ of the nation is literate. The government is keenly aware that education has a direct effect on reproduction as well as generating jobs and income. Women in Rwanda who have little or no education have an average of 2.6 more children than those who have at least a secondary education. Rwanda also promotes female empowerment: $56 \%$ of its lawmakers are women.
Rwanda also hopes to exploit 'family planning by television' - the close correlation between economic growth and decreased fertility. (As couples get wealthier and have television sets in the bedroom, they have fewer children.) Rwanda's economic development plan, Vision 2020, calls for a per capita income of 600,000 francs (US $\$ 1,000$ ) by 2020 , up from 180,000 francs today. Yet if the country's population continues to soar, such development - and any effects of contraception - will be elusive. Here we focus on the final ingredient in the recipe: family planning as a positive and essential health service.

\section{RWANDA'S EXPERIENCE}

Rwandan culture, government and religious institutions have historically discouraged family planning. Furthermore, the Catholic Church manages about half of the health centres in the country and refuses to provide contraceptives on site, even to men with HIV.

Despite these challenges, the nation has made significant progress in making family planning more widely available through hospitals and health centres. Some government and partner programmes have even set up family-planning centres just outside the doors of the Catholic facilities. In our experience, when women are offered family-planning measures discreetly and for free, they take them. The women call this kuba kuri gahunda: being on target. Policymakers might also call it a no-regrets policy. Contraception is relatively cheap and reducing the number of unplanned pregnancies has other benefits: "The choices are it lowers materstark:restrict nal mortality and stark: restrict reduces the numpopulation growth or remain in poverty." ber of abortions, which are illegal, and therefore risky, in Rwanda.

Before the genocide, a 1992 survey found that $13 \%$ of married women were using modern contraceptives. This number had dropped to just $4 \%$ in 2000 . By 2005 it had risen to $10 \%$ and preliminary survey results indicate that by 2008 , uptake was $27 \%$. Rwanda aims to boost contraceptive use to $70 \%$ for married women by 2020 (in line with most industrialized nations) and to reduce average family size to three children. Demographic changes are slow, but are heading in the right direction: in 2005, the average family size was 5.9; by 2007 , it had fallen to 5.5 .

Even with a clear national strategy, family-planning policies can be easily misconstrued. A national push for free voluntary vasectomies has had some unintended consequences. In the past year, the government has encouraged male sterilization as one of the most effective methods of contraception. But recently, the Rwandan health ministry had to defuse concerns, caused by confused press reports, about whether the policy might be targeting the poor. Although the procedure is unlikely to make a substantial dent in population growth, it is informing a broader discussion about the need for family planning. In addition, increasing men's awareness is altering the perception of family planning as solely a woman's concern.

Public discourse is also changing. Today, politicians and church leaders speak of kubyara aba ushoboye kurera - 'giving birth to those you are able to raise fairly'. Many traditional Rwandan names, however, are religious and passive in their interpretation: Harerimana ('only God raises'), Habyarimana ('only God gives birth') and Hakizimana ('only God gives wealth or healthy life').

\section{TIME TO ACT}

Rwanda's neighbours do not share its vision. It is fashionable for leaders of poor nations to speak of environmental destruction and the challenges of achieving the UN Millennium Development Goals to end poverty. Most remain tight-lipped on population control. The global population is projected to keep rising - to 7 billion later this year, and to 9 billion by 2050 . Nearly a billion of those additional people will be Africans. This growth will probably fuel increased poverty, contribute to institutional and government failure, and generally constrict development.

Family planning is cheap. The UN estimates that for every dollar invested there is a threefold economic return. Simply put, countries interested in boosting their economies can make no better investment than in family planning.

Sadly, international organizations and agencies are not paying attention, probably because they are afraid of stoking religious or political flames. This scenario has played out repeatedly in global health priorities: the Worldwatch Institute, headquartered in Washington DC, estimates that, between 1994 and 2007, family-planning aid dropped from $30 \%$ to $12 \%$ of overall aid. Until wealthier nations and large donors step up to fund family planning, poor nations themselves will have to take the lead. For those that choose this path - as Rwanda is doing the rewards will be healthier, wealthier and smaller populations.

Josh Ruxin is an assistant clinical professor of public health at Columbia University in New York and directs the Access Project in Rwanda; Antoinette Habinshuti is the deputy country director for Partners in Health in Rwanda.

e-mail:joshruxin@columbia.edu 
which says that the larger a sample, the more closely the sample characteristics match those of the parent population.

Insurance companies had been limiting the number of policies they sold. As policies are based on probabilities, each policy sold seemed to incur an additional risk, the cumulative effect of which, it was feared, could ruin a company. Beginning in the eighteenth century, companies began their current practice of selling as many policies as possible, because, as Bernoulli's law of large numbers showed, the bigger the volume, the more likely their predictions are to be accurate.

\section{JULIA COLLINS From bridges to DNA}

\section{University of Edinburgh, UK}

When Leonhard Euler proved to the people of Königsberg in 1735 that they could not traverse all of their seven bridges in one trip, he invented a new kind of mathematics: one in which distances didn't matter. His solution relied only on knowing the relative arrangements of the bridges, not on how long they were or how big the land masses were. In 1847, Johann Benedict Listing finally coined the term 'topology' to describe this new field, and for the next 150 years or so, mathematicians worked to understand the implications of its axioms.

For most of that time, topology was pursued as an intellectual challenge, with no expectation of it being useful. After all, in real life, shape and measurement are important: a doughnut is not the same as a coffee cup. Who would ever care about 5-dimensional holes in abstract 11-dimensional spaces, or whether surfaces had one or two sides? Even practical-sounding parts of topology such as knot theory, which had its origins in attempts to understand the structure of atoms, were thought to be useless for most of the nineteenth and twentieth centuries.

Suddenly, in the 1990s, applications of topology started to appear. Slowly at first, but gaining momentum until now it seems as if there are few areas in which topology is not used. Biologists learn knot theory to understand DNA. Computer scientists are using braids - intertwined strands of material running in the same direction - to build quantum computers, while colleagues down the corridor use the same theory to get robots moving. Engineers use one-sided Möbius strips to make more efficient conveyer belts. Doctors depend on homology theory to do brain scans, and cosmologists use it to understand how galaxies form. Mobile-phone companies use topology to identify the holes in network coverage; the phones themselves use topology to analyse the photos they take.

It is precisely because topology is free of distance measurements that it is so powerful. The same theorems apply to any knotted DNA, regardless of how long it is or what animal it comes from. We don't need different brain scanners for people with different-sized brains. When Global Positioning System data about mobile phones are unreliable, topology can still guarantee that those phones will receive a signal. Quantum computing won't work unless we can build a robust system impervious to noise, so braids are perfect for storing information because they don't change if you wiggle them. Where will topology turn up next?

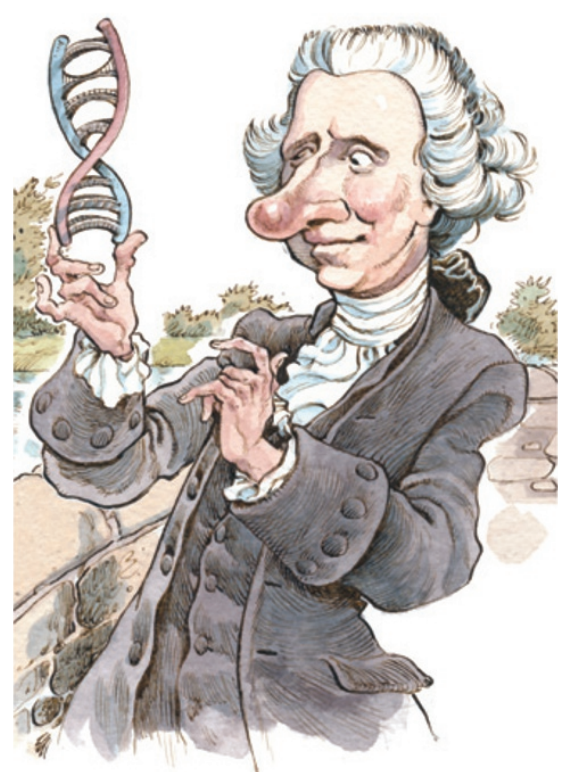

CHRIS LINTON

\section{From strings to nuclear power}

Loughborough University, UK

Series of sine and cosine functions were used by Leonard Euler and others in the eighteenth century to solve problems, notably in the study of vibrating strings and in celestial mechanics. But it was Joseph Fourier, at the beginning of the nineteenth century, who recognized the great practical utility of these series in heat conduction and began to develop a general theory. Thereafter, the list of areas in which Fourier series were found to be useful grew rapidly to include acoustics, optics and electric circuits. Nowadays, Fourier methods underpin large parts of science and engineering and many modern computational techniques.

However, the mathematics of the early nineteenth century was inadequate for the development of Fourier's ideas, and the resolution of the numerous problems that arose challenged many of the great minds of the time. This in turn led to new mathematics. For example, in the 1830s, Gustav Lejeune Dirichlet gave the first clear and useful definition of a function, and Bernhard Riemann in the 1850s and Henri Lebesgue in the 1900 s created rigorous theories of integration. What it means for an infinite series to converge turned out to be a particularly slippery animal, but this was gradually tamed by theorists such as Augustin-Louis Cauchy and Karl Weierstrass, working in the 1820 s and 1850s, respectively. In the 1870s, Georg Cantor's first steps towards an abstract theory of sets came about through analysing how two functions with the same Fourier series could differ.

The crowning achievement of this mathematical trajectory, formulated in the first decade of the twentieth century, is the concept of a Hilbert space. Named after the German mathematician David Hilbert, this is a set of elements that can be added and multiplied according to a precise set of rules, with special properties that allow many of the tricky questions posed by Fourier series to be answered. Here the power of mathematics lies in the level of abstraction and we seem to have left the real world behind.

Then in the 1920s, Hermann Weyl, Paul Dirac and John von Neumann recognized that this concept was the bedrock of quantum mechanics, since the possible states of a quantum system turn out to be elements of just such a Hilbert space. Arguably, quantum mechanics is the most successful scientific theory of all time. Without it, much of our modern technology - lasers, computers, flat-screen televisions, nuclear power would not exist.

\section{CORRECTIONS}

In the Comment article 'Buried by bad decisions' (Nature 474, 275-277), the statement "we will save lives by pushing a trolley into a person but not a person into a trolley" refers to an incorrect reference. The correct one is J. D. Greene et al. Science 293, 2105-2108 (2001).

The Comment article 'Crowd control in Rwanda' (Nature 475, 572-573) should have stated that family-planning aid dropped from $30 \%$ to $12 \%$ of overall health aid, not overall aid. 